\title{
A Compact Design of Transparent Microstrip Antenna For Wireless Car-to-Car Communication System
}

\author{
Yusnita Rahayu* \\ Department of Electrical Engineering, \\ Universitas Riau \\ Pekanbaru, Indonesia
}

\author{
Raja D.A \\ Department of Electrical Engineering, \\ Universitas Riau \\ Pekanbaru, Indonesia
}

\author{
Yoga B. P \\ Department of Electrical Engineering, \\ Universitas Riau \\ Pekanbaru, Indonesia
}

*corresponding author: Yusnita Rahayu, yusnita.rahayu@lecturer.unri.ac.id

\begin{abstract}
In this paper, a compact design of transparent rectangular microstrip antenna with a slotted ground plane has been designed and evaluated to support Intelligent Transportation System (ITS). The proposed antenna consists of a single element using transparent conductive film AgHT-4 layered on a plain glass substrate, fed by a single $50 \Omega \mathrm{SMA}$ port. The antenna is working on $5.9 \mathrm{GHz}$ based on IEEE 802.11p for Wireless Access in Vehicular Environment (WAVE) Standard. The design concept is to have arc shape slot out of the ground plane of a microstrip patch antenna to enable wideband frequency. The proposed antenna provides ultra wide impedance bandwidth around $750 \mathrm{MHz}(5.48-6.23 \mathrm{GHz})$ at a center frequency of $5.9 \mathrm{GHz}$. The proposed transparent antenna has a directivity gain of $6.266 \mathrm{dBi}$.
\end{abstract}

Keywords-transparent antenna, Arc shape slot antenna, car to car communication, ITS

\section{INTRODUCTION}

The automotive industry in few decades rapidly growing and become one of the crucial things in modern civilization. This industry never has a research and development of using efficient communication between vehicle to vehicle and vehicle to roadside infrastructure.[1]. Vehicle to vehicle or can refers to the car to car communication is a new approach of technology that allows vehicles to communicate with each other based on the new standard IEEE 802.11p for WAVE. It designates to IEEE 802.11, the basis products marketed as WiFi. It is required to support ITS, in the permitted ITS band of $5.9 \mathrm{GHz}$. IEEE 802.11p standard has 7 channels of $10 \mathrm{MHz}$ bandwidth in the $5.9 \mathrm{GHz}$ band, this $10 \mathrm{MHz}$ channel width is obtained from $75 \mathrm{MHz}$ spectrum divide into seven intervals, range from $5.85 \mathrm{GHz}$ to $5.925 \mathrm{GHz}[2]$. The application offered by this technology range from safety, improve the efficiency of an autonomous vehicle to infotainment services[1][3].

As wireless communication is rapidly growing and demand of the wireless device pushing the limit of antenna design. Many researchers have been conducted on optically transparent antenna design, make it possible to attach on the see-through surface. The transparent conductive films allow the transmission of electric current, while still retaining the optical transparency[4].

There are several research papers on transparent conductive materials[4-7]. At least, there are three main types of transparent conductive films used today, such as indium tin oxide (ITO), flourine-doped tin oxide (FTO) and silver coated polyester (AgHT) films [4]. A trade-off from the materials must be considered on these conductive film where optical transparency has to be sacrificed for better conductivity. AgHT film has been recorded lower than $70 \%$ optical transparency to have an effective conductivity[4][7].

A microstrip patch antenna configuration commonly consists of three layers sandwich structured, first layer is the antenna patch, under the patch layer consist of a dielectric substrate and the third layer is the ground plane. The conductor of the patch is usually made of copper and sometimes can be replaced by any conductive material depend on antenna application needed. The shape of the radiating patch can be into various shapes such as square, circular, rectangular elliptical or other irregular shapes. However, most commonly used shapes are square, rectangular and circular due to its commonly available fabrications and ease of design and analysis. Microstrip antenna has many advantages, such as low profile and low volume, cheap fabrication cost, easy to mass production.[6]

This paper proposes a rectangular microstrip transparent antenna using an arc shape slot on the ground plane for the car-to-car communication system. The arc shape slot was previously presented in[4]. The design used transparent conductive film AgHT-4 as conductive part and layered on a glass substrate to improve optical transparency resulted in this antenna design suitable for applied on cars windshield or windows. This is because it did not block visibility from inside of the car. Microstrip antenna design provides a low profile and low volume and eases of fabrication and mass production.

The rest of the paper is organized as follows. Section II presents the antenna design. In section III presents the proposed antenna simulation and parametric studies. And the final section IV is the conclusion of entire work in this paper. 


\section{ANTENNA DESIGN}

The proposed antenna design of $5.9 \mathrm{GHz}$ single element transparent antenna is shown in Figure 1. Moreover, the dimension of each parameter is listed in Table 1. The suggested antenna is designed on a substrate using plain glass with relative permittivity of 7 with a thickness of $2 \mathrm{~mm}$. The substrate is designed to compact enough $(60 \times 45 \mathrm{~mm} 2)$ to stabilize the antenna structure, including gain and the value not change after increasing the dimension of the glass substrate [3].

Both patch and ground plane are made from material silver-coated conductive thin films or AgHT-4 with $\sigma=22000$ $\mathrm{S} / \mathrm{m}$ and using the same thickness of $0.175 \mathrm{~mm}$. The proposed antenna was determined from the known values of AgHT-4 and er using the following formulas [4][6] :

The calculation formula for Patch Width (Wp) dimension:

$W=\frac{C}{2 f} \sqrt{ } \frac{2}{\varepsilon r+1}$

Where $\mathrm{c}=$ velocity of light in free space

The Effective Dielectric Constant $\left(\varepsilon_{\text {reff }}\right)$ is calculated as :

creff $=\frac{\varepsilon_{r}+1}{2}+\frac{\varepsilon_{r}-1}{2}\left(1+\frac{12 h}{W}\right)^{-\frac{1}{2}}$

Calculation formula of extended incremental length $(\Delta \mathrm{L})$ is given by:

$\Delta \mathrm{L}=0.412 \mathrm{~h}\left(\frac{\varepsilon_{\text {reff }+0.3}}{\varepsilon_{\text {reff }-0.258}}\right)\left(\frac{W / h+0.264}{W / h^{+0.8}}\right)$

The calculation formula for Effective Patch Length $\left(\mathrm{L}_{e f f}\right)$ is :

$L_{e f f}=\frac{c}{2 f_{r} \sqrt{\varepsilon_{\text {reff }}}}$

The calculation formula for the patch length dimension is :

$L=L_{\text {eff }}-2 \Delta L$

The calculation formula for Substrate Length (Ls), Substrate Width (Ws), Ground Plane Width (Wg) and Ground Plane Length $(\mathrm{Lg})$ is given by:

$\mathrm{Ls}=\mathrm{Lg}=6 \mathrm{~h}+\mathrm{L}$

$\mathrm{Ws}=\mathrm{Wg}=6 \mathrm{~h}+\mathrm{W}$

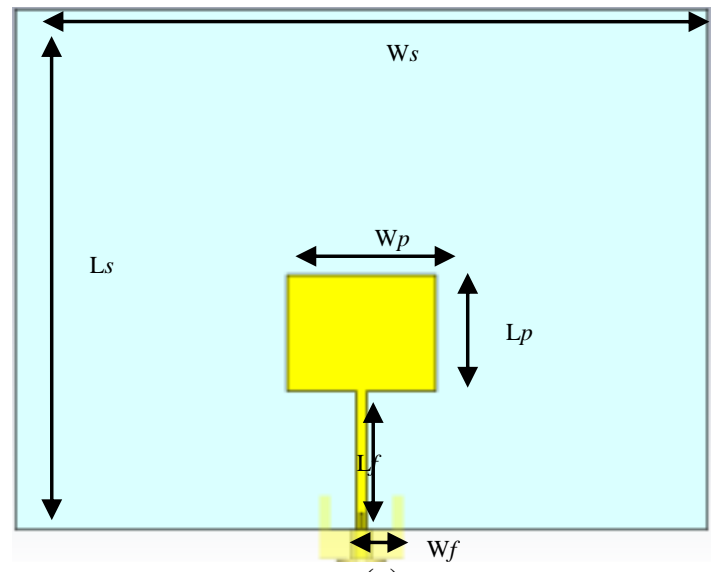

(a)

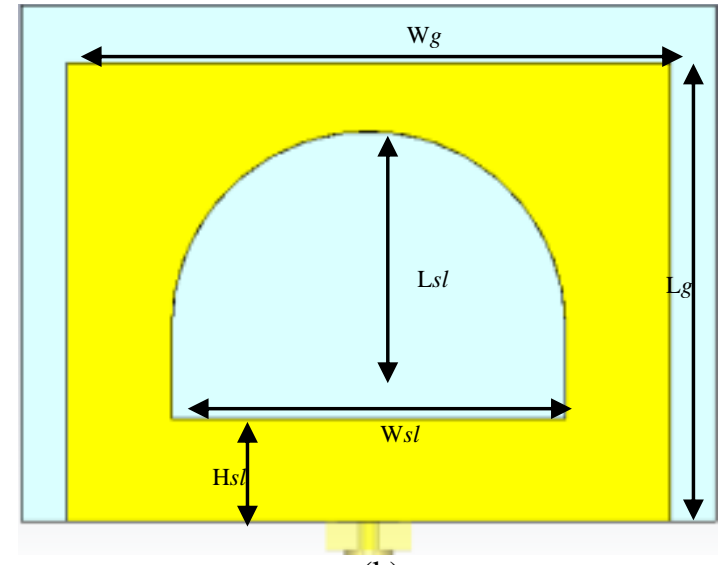

(b)

Figure 1. computed model of proposed antenna design (a)Front view (b)Back view.

The proposed antenna design uses center microstrip line feed. The calculated dimension of the patch, substrate, ground plane, and feeding line are listed in table 1:

Table 1. the dimension of the proposed antenna design.

\begin{tabular}{|c|c|}
\hline Parameters & Dimension (mm) \\
\hline $\mathrm{W} p$ & 18 \\
\hline $\mathrm{L} p$ & 10 \\
\hline $\mathrm{W} f$ & 12 \\
\hline $\mathrm{L} f$ & 60 \\
\hline $\mathrm{W} s$ & 45 \\
\hline $\mathrm{L} s$ & 52 \\
\hline $\mathrm{W} g$ & 39 \\
\hline $\mathrm{Lg}$ & 34 \\
\hline $\mathrm{L} s l$ & 17 \\
\hline $\mathrm{W} s l$ & 25 \\
\hline H $s l$
\end{tabular}

\section{ANTENNA SIMULATION AND PARAMETRIC STUDIES}

To obtain the optimum result suitable frequency for IEEE 802.11p, several parametric studies have been done to investigate the effect of varying parameters on the proposed antenna. Some parameters are analyzed including the effect of varying width of patch dimension, length of patch dimension, with arc-shape and without arc-shape effect, and size of the ground plane. Table 2 shows the characterization of the patch width dimension of the antenna. From the table, it is noticed that with $18 \mathrm{~mm}$ of patch width, the frequency of $5.9 \mathrm{GHz}$ is achieved. 
Table 3. Patch length dimension characterization

\begin{tabular}{|c|c|r|r|}
\hline $\mathrm{Wp}$ & Lp & Frequency & $\begin{array}{c}\text { S- } \\
\text { Parameter } \\
\text { S1.1 }\end{array}$ \\
\hline $18 \mathrm{~mm}$ & $9 \mathrm{~mm}$ & $5.908 \mathrm{GHz}$ & -25.461 \\
\hline $18 \mathrm{~mm}$ & $10 \mathrm{~mm}$ & $5.905 \mathrm{GHz}$ & -23.542 \\
\hline $18 \mathrm{~mm}$ & $11 \mathrm{~mm}$ & $5.899 \mathrm{GHz}$ & -22.580 \\
\hline $18 \mathrm{~mm}$ & $12 \mathrm{~mm}$ & $5.893 \mathrm{GHz}$ & -21.467 \\
\hline
\end{tabular}

Table 3.shows the characterization of antenna patch length dimension. Patch width (Wp) is kept constant of $18 \mathrm{~mm}$. From table 3 . The antenna patch length of $9 \mathrm{~mm}$ improves the return loss.

Table 4. Characterization ground width dimension

\begin{tabular}{|c|c|c|c|}
\hline Lg & Wg & Frequency & $\begin{array}{c}\text { S- } \\
\text { Parameter } \\
\text { S1.1 }\end{array}$ \\
\hline $39 \mathrm{~mm}$ & $50 \mathrm{~mm}$ & $5.899 \mathrm{GHz}$ & -28.954 \\
\hline $39 \mathrm{~mm}$ & $52 \mathrm{~mm}$ & $5.908 \mathrm{GHz}$ & -25.461 \\
\hline $39 \mathrm{~mm}$ & $54 \mathrm{~mm}$ & $5.914 \mathrm{GHz}$ & -23.112 \\
\hline $39 \mathrm{~mm}$ & $56 \mathrm{~mm}$ & $5.923 \mathrm{GHz}$ & -21.372 \\
\hline
\end{tabular}

Table 4 shows the effect of varying ground width dimension. From table 4, varying ground width dimension has shifted the frequency. Ground width of $50 \mathrm{~mm}$ provides frequency closed to $5.9 \mathrm{GHz}$.

Table 5. Ground length dimension characterization

\begin{tabular}{|c|c|c|c|}
\hline Wg & Lg & Frequency & $\begin{array}{c}\text { S- } \\
\text { Parameter } \\
\text { S1.1 }\end{array}$ \\
\hline $50 \mathrm{~mm}$ & $38 \mathrm{~mm}$ & $5.905 \mathrm{GHz}$ & -25.713 \\
\hline $50 \mathrm{~mm}$ & $39 \mathrm{~mm}$ & $5.899 \mathrm{GHz}$ & -28.954 \\
\hline $50 \mathrm{~mm}$ & $40 \mathrm{~mm}$ & $5.899 \mathrm{GHz}$ & -33.495 \\
\hline $50 \mathrm{~mm}$ & $41 \mathrm{~mm}$ & $5.902 \mathrm{GHz}$ & -40.480 \\
\hline
\end{tabular}

Table 5. shows the effect of varying ground length dimension. From table 5. varying ground length dimensions improve the return loss. The ground length of $41 \mathrm{~mm}$ gives the lowest return loss of $-40.480 \mathrm{~dB}$.

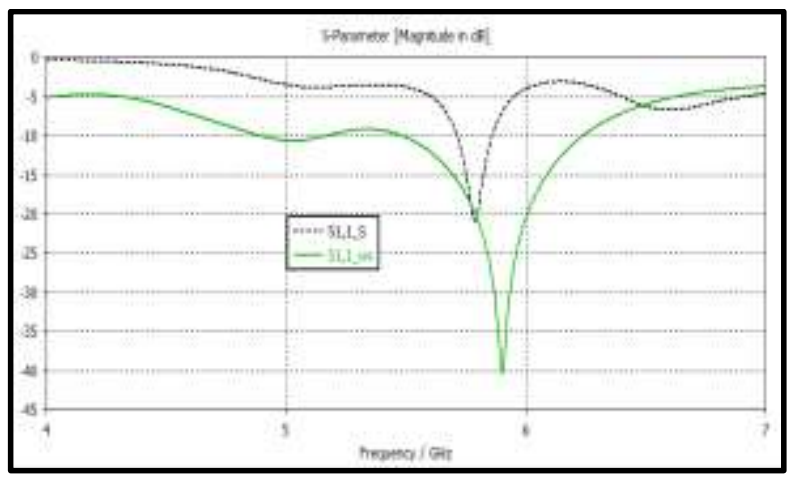

Figure 2. Return loss with arc shape slot (S1.1_S) and without arc shape slot (S1.1_ws)

Figure 2. shows the return loss for both antennas with and without the arch shape slot. It shows that with an arc shape slot, the lowest return loss of $40.480 \mathrm{~dB}$ is obtained at 5.9 $\mathrm{GHz}$.

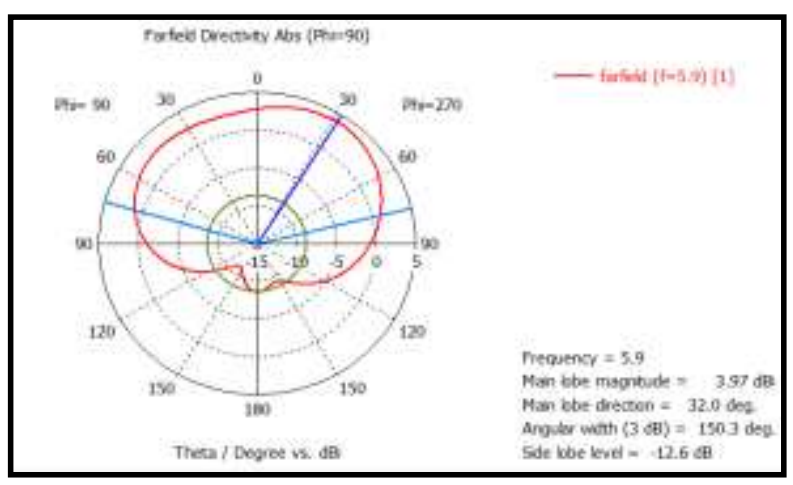

Figure 3. polar view radiation pattern of transparent patch antenna.

Figure 3 presents the broad directional radiation pattern of the antenna. This proposed antenna works on $5.9 \mathrm{GHz}$ with directivity gain of $6.266 \mathrm{dBi}$.

\section{CONCLUSION}

A single element microstrip transparent antenna has been designed and simulated at $5.9 \mathrm{GHz}$ for car-to-car communications. The radiation pattern observed has broad directional pattern and suitable to be attached at any part on the vehicle. The broad bandwidth of $750 \mathrm{MHz}$ is achieved by adding an arc shape slot on the ground plane. Several parametric analyses are already investigated. The gain of $6.266 \mathrm{dBi}$ is obtained.

\section{REFERENCES}

[1] Quack, D., Meuleners, M., \& Hommen, S, "Simulation-based evaluation of MIMO antenna systems in car-to-car communication", In Antennas and Propagation (EuCAP), 2014 8th European Conference, pp. 3049-3052, IEEE, 2014.

[2] Tomar, R., Prateek, M. and Sastry, H.G., 2017, "Analysis of beaconing performance in IEEE $802.11 \mathrm{p}$ on vehicular ad-hoc environment", 4th IEEE Uttar Pradesh Section International Conference on Electrical, Computer and Electronics (UPCON), pp. 692-696, IEEE, 2017.

[3] Ahmed, S. A., Ariffin, S. H., \& Fisal, N, "Overview of wireless access in vehicular environment (WAVE) protocols and standards", Indian Journal of Science and Technology, 6(7), 4994-5001, 2013.

[4] Azini, A. S., Kamarudin, M. R., Rahman, T. A., Iddi, H. U., Abdulrahman, A. Y., \& Jamlos, M. F. B, "Transparent antenna design 
for WiMAX applicatio", Progress In Electromagnetics Research, 138, 133-141, 2013

[5] Song, H. J., Hsu, T. Y., Sievenpiper, D. F., Hsu, H. P., Schaffner, J., \& Yasan, E, "A method for improving the efficiency of transparent film antennas", IEEE Antennas and Wireless Propagation Letters, 7, 753756, 2008.

[6] Karthick, M, "Design of $2.4 \mathrm{GHz}$ patch antennae for WLAN applications", Computing, Communication and Information Systems (NCCCIS), IEEE Seventh National Conference, pp. 1-4, 2015.
[7] Poliks, M. D, Sung, Y. L, Lombardi, J, Malay, R, Dederick, J, Westgate, C. R., \& Daly, C, "Transparent antennas for wireless systems based on patterned indium tin oxide and flexible glass", Electronic Components and Technology Conference (ECTC), IEEE 67th, pp. 1443-1448, IEEE, 2017.

[8] Wahid, W. I., Kamarudin, M. R., Khalily, M., \& Peter, T, "Circular Polarized Transparent Antenna for 5. $8 \mathrm{GHz}$ WLAN Applications", Progress In Electromagnetics Research, 57, 39-45, 2015. 